\title{
Toward a Psychological Explanation of Near-Death Experiences: A Response to Dr. Grosso's Paper
}

\author{
Bruce Greyson \\ Department of Psychiatry \\ University of Michigan School of Medicine
}

\section{INTRODUCTION}

Michael Grosso, in his elegant review of various hypotheses intended to explain near-death experiences (NDEs) (1981), dismissed psychological explanations as reductionistic and unable to account adequately for the NDE. The present paper is a restatement of the case for psychological interpretations of the NDE; it is intended to forestall the premature rejection of psychodynamic approaches to the study of NDEs. This paper does not propose a comprehensive psychological model for the NDE; we do not know enough about NDEs yet to formulate comprehensive models, and it may be that when we do know more about these phenomena, we will discover that certain elements are not reducible to psychological constructs. We do know enough, however, about human behavior to state that any comprehensive interpretation of the NDE eventually developed must take into account the role played by psychological defenses.

Grosso noted the difficulties inherent in labeling NDE reporters as having been "dead," since they have been restored to vital functioning and in that regard may differ critically from those who "stay dead." However, he also noted the temptation to consider "dead" all those who have temporarily lost all vital functioning and who would have "remained dead" if not for medical intervention. This dilemma hints at the first problem in the interpretation of NDEs: their degree of relevance to death or dying.

The NDE does not tell us directly what death is like, nor what dying is like. There are at least four critical points at which we may question the correspondence between an NDE report and the experience of those who die. Firstly, those near-death survivors who choose 
to report their experiences to others may have had very different experiences from those survivors who choose not to report them; indeed, the type of experience recalled may be critical to an individual's decision about whether to report the experience or not. Secondly, those individuals who, upon surviving a close brush with death, recall their experiences may have had very different experiences from those who recall nothing upon revival; again, the nature of the experience may be critical to the process of recalling or repressing the memory of the experience. Thirdly, those individuals who survive a close brush with death may have had very different experiences from those who do not survive; conceivably, the type of experience could influence whether or not one survives the near-death event. And fourthly, it is possible that even if near-death survivors and non-survivors have similar experiences, those who survive experience only the initial and perhaps atypical stages of the dying process; and again, it is conceivable that how far one progresses into the dying experience influences whether or not one survives.

The significance of this series of questions is that what we are studying is not the NDE itself, but a voluntary recounting of a memory of the NDE. Whether or not psychological defenses are operative in the elicitation of an NDE, the recall of the experience and the motivation to recount one's recollection certainly are subject to psychological interpretation. Thus an exploration of psychological mechanisms may be necessary for understanding the NDE report, regardless of one's explanation of the NDE itself.

\section{COULD A PSYCHOLOGICAL HYPOTHESIS EXPLAIN THE NDE?}

\section{Consistency and Universality of NDEs}

Grosso listed three components of the NDE that he felt demanded explanation by any satisfactory theory of near-death phenomena. The first of these three components is the apparent consistency and universality of NDEs. Grosso cited evidence from the literature attesting to the independence of NDE reports from religious background, demographic factors, and cultural variables. He did warn that further work needs to be done to substantiate the claim of consistency, and in fact Drab (in press) has found that, on more detailed investigation of the "tunnel experience," this consistency appears to diminish.

However, the mere fact, if fact it is, of universality of experience contributes little to an interpretation of the experience. Consistency may be an indication of objective reality, but it may also be an 
indication of a physiological imperative or a common psychological predisposition. Grosso himself cited the example of delirium tremens, an illusory phenomenon based on impaired physiology with essential elements consistent across cultures and personalities.

One example of a psychological explanation for the consistency and universality of NDEs is the birth-memory-activation model first described in detail by Grof and Halifax (1977). Grof and Halifax suggested that a close brush with death may trigger a retrieval of the individual's long-suppressed memories of the birth process. The feeling of peace, the ineffability, and the spatio-temporal transcendence of the NDE recapitulate the subjective experience of intrauterine life; the propulsion headfirst through a dark, noisy, enclosed, tunnel-like space represents travel through the cervical canal; and the emergence in to the light and freedom in the presence of a commanding figure reflect the subjective experience of delivery. While there are questions about the newborn infant's ability to perceive and remember experiences in such detail and imperfect correspondence between the prototypical NDE and the birth experience, this model illustrates the concept of a nearly universal prior experience which may serve as a template on which the NDE reporter might organize his or her understanding, and subsequent retelling, of the NDE.

\section{Paranormal Aspects of NDEs}

Grosso listed, as the second component of NDEs that requires explanation, the paranormal material sometimes reported in NDEs. He felt that the significance of this component lay partly in its suggestion that NDEs express more than just wish fulfillment or selfserving fantasy. However, far from dispelling the notion of NDEs as self-serving wish fulfillment, the documentation of paranormal elements may provide indirect evidence for the psychological needsubserving aspect of the NDE.

In $^{-a}$ a widely used paradigm of paranormal functioning, Stanford's psi-mediated instrumental response (PMIR) model, paranormal events are conceived as occurring only in response to specific needs of the individual. Relevant basic assumptions of the PMIR model, which has received substantial experimental support, stipulate (Stanford, 1974, pp. 43-45) that:

1. In the presence of a particular need the organism uses psi (ESP), as well as sensory means, to scan its environment for objects and events relevant to that need and for information crucially related to such objects or events.... 
2. When extrasensory information is thus obtained about needrelevant objects or events (or information crucially related thereto), a disposition toward psi-mediated instrumental response (PMIR) occurs ....

3. Preparation for or production of PMIR often involves such changes as motivational or emotional arousal, attention-focusing responses, and other preparation for response ....

4. All else being equal, the strength of the disposition toward PMIR is directly related to: (a) the importance or strength of the need(s) in question; (b) the degree of need-relevance of the need-relevant object or event; and (c) the closeness in time of the potential encounter with the need-relevant object or event.

Experimental manipulation of the strength of psychological needs has demonstrated that the tendency to produce paranormal effects is, as predicted, positively related to the strength of the need subserved by the PMIR (Stanford and Associates, 1976). Thus, the occurrence of paranormal material in the NDE may support the claim that the NDE is at least in part a response to some psychological need of the experiencer.

\section{Beneficial Effects of NDEs}

Grosso listed, as the third component of NDEs that requires explanation, the modification of outlook, affective states, values, and goals often reported in accounts of NDEs. He felt that the adaptive potential of NDEs seemed incongruous with thinking of them as illusory or pathological.

Few clinicians would agree with Grosso that this is an incongruous state of affairs. In fact, many psychologists and psychiatrists regard the ego disruption characteristic of severe psychopathology as a multipotential state which may lead either to incapacitating disorganization, or to intense self-knowledge and growth. Some psychiatrists interpret schizophrenia as a positive development that reveals truths and opens new paths toward greater moral values (e.g., Siirala, 1963).

The British psychiatrist R. D. Laing's "psychedelic model" of schizophrenia focuses on the creative uses certain schizophrenics have made of their unusual experiences, and suggests that such patients should be regarded as persons embarked on a voyage of selfdiscovery (Siegler, Osmond, and Mann, 1969). Laing asserts that schizophrenia is a natural way of healing alienation and that many schizophrenics can emerge better than they were before: "Madness 
need not be all breakdown . . . It may also be breakthrough. It is potential liberation and renewal as well as enslavement and existential death" (1967, p. 93).

Mainstream American psychiatrists also acknowledge the potential of psychosis to help an individual become a fuller and better-integrated person. Arieti, in his National Book Award-winning treatise on schizophrenia, stated that some schizophrenic experiences can strengthen and enrich human life (1974, pp. 379-381):

The extreme individualism of the schizophrenic, his use of paleosymbols, the expanded capacity for symbolism, his paleologic thinking permit an enlargement of the human experience, can open new horizons and lead to new paths of feeling and understanding .... What appears unusual, illogical, imaginary, or exclusively the result of psychosis, should be seen not only in the restricted sense of being outside of reality but also of being an expansion of reality .... Together with the greatest error and greatest impoverishments I have at times found great truths and enrichments inherent in psychosis, truths and enrichments which transcend the parochialism of time and space.

"Psychedelic" or "mind-manifesting" experiences similar to those precipitated by hallucinogenic drugs or religious conversion experiences are recognized as occurring spontaneously in psychosis, and are acknowledged to impart increased perceptual sensitivity and unique insights to the psychotic patient (Bowers and Freedman, 1966).

The idea that pathological states can lead to positive growth is a basic assumption of the theory underlying crisis intervention, an efficacious and widely practiced psychotherapeutic technique. The concept of opportunity for growth in crisis, as developed by the pioneers of crisis theory, Lindemann (1944) and Caplan (1964), assumes that in periods of stress, a person enters a state of disequilibrium characterized by high anxiety and helplessness, in which his or her ego patterns, having been overwhelmed, are more open than usual to positive and corrective influence. Certain marathon groups are designed to facilitate the breakdown and restoration of personality in achieving the therapeutic result (Yalom, 1975). Finally, psychoanalytic explanations of the therapeutic effect of shock treatments speculate that the shock initiates a deep regression of the individual to a very primitive level, from which a new and better adaptation may develop (Fenichel, 1945). Thus the idea that severe mental dysfunction may lead to positive personality transformation has a long tradition of acceptance and utilization in psychology and psychiatry. Might NDEs be a specific case in point?

Mystical states have been described as one kind of "regression in the service of the ego," a reversion to a more primitive coping style 
which serves an adaptive function (Prince and Savage, 1966). The renunciation of worldly attachments preparatory to mystical states facilitates the return to earlier levels of functioning; the ineffability of the mystical experience reflects the preverbal stage of development to which the individual is regressed; the noetic quality of the experience corresponds to the "realness" of infantile experiences, when the individual had a primal, immediate, and unquestioned trust in his or her sensations; the ecstatic feeling represents regression to a blissful nursing experience when all the individual's needs were met; and the feeling of cosmic unity recapitulates the loss of ego boundaries in the symbiotic stage of development to which the individual is regressed.

Clark (1966) explained the profound ability of mystical experiences to effect change by invoking this interpretation of the mystical state as regression. He suggested that such experiences produce change because earlier levels of development are characterized by increased lability or impressionability; the infant's blissful state of relaxation facilitates freer exchange of ideas; and the helplessness of the infantile state fosters a sense of awe.

NDEs may be interpreted as one type of mystical state, and thus as an example of regression. I (1981a) reviewed a number of reductionistic psychodynamic hypotheses to explain positive personality transformations following NDEs among suicide attempters. I concluded that NDEs might reduce an individual's suicidal ideation by a variety of psychological mechanisms, including (1) inducing a sense of cosmic unity to replace the suicide attempter's feelings of alienation; (2) inducing a primary sense of worth not contingent upon external circumstances; (3) facilitating a decathexis of unmet worldly goals and a view of one's losses as irrelevant from a transpersonal perspective; (4) enhancing one's sense of value or meaning of life; (5) aiding one, through the life review, to reevaluate old conflicts and differentiate real from neurotic guilt; (6) providing an ego death which may serve as a substitute for death of the self; (7) transcending the ego, which may help the suicide attempter escape from painful feelings; (8) renewing or validating one's sense of being alive; (9) enhancing self-esteem through having survived, or having been assured (subjectively) of post-mortem survival; (10) enhancing self-esteem through having faced death serenely; (11) mobilizing and discharging destructive energies; (12) instilling a fear of repeating an unpleasant close brush with death; and/or (13) effecting secondary gains which might reduce suicidal intent. Thus, an interpretation of the NDE as a form of regression may be quite compatible with its positive transformative effects. 
In summary, then, a psychological explanation of the NDE is capable of addressing all three puzzling components of the phenomenon that Grosso asserted any explanation of the NDE must do: its consistency or universality, its paranormal dimension, and its beneficial effects upon the individual.

\section{COULD THE NDE SERVE A PSYCHOLOGICAL FUNCTION?}

Consistency with the data of NDE reports is just one requirement of an adequate explanation of the NDE. A satisfactory theory should also contribute something unique to our understanding of NDEs. In the present case, it would be pointless to determine whether a psychological interpretation could address the facts about NDEs adequately, unless it was anticipated that the NDE might serve some psychological purpose.

Grosso noted the difficulty in reconciling any purpose with a state of imminent death: once an irreversible process of death begins, what biological function could be ascribed to any experience, let alone a transcendental one? If this apparent paradox is accepted, there are two possible solutions: (1) that death is not cessation, the solution Grosso offered; or (2) that experiences can occur without any biological purpose. Either solution would require substantial revision of our customary attitude toward our biological functioning.

However, there are two less drastic alternatives if one questions the basic assumptions of Grosso's paradox: (3) that the biological function served by the NDE may be beneficial not to the dying individual, but to his reproductive group; or (4) that the NDE may not in fact occur at the point of death, but rather during a time of vital functioning.

\section{Biological Utility of the NDE for Others}

An NDE occurring on the threshold of death, when the dying individual has passed the point of personal rescue, could serve an adaptive purpose for those who witness the dying process. That is, the NDE may have evolved as an adaptive mechanism that may influence the dying person's behavior so as to promote the survival of others. The robin about to be overtaken by a hawk will emit a thin, reedy whistle to warn the rest of the flock; the honeybee whose hive is threatened by an intruder will commit suicide by stinging the invader. Many animals have evolved altruistic behavior elicited by the threat of imminent death. Perhaps the behavioral relaxation and equanimity produced by the NDE is adaptive for the dying person's 
peers to witness. The apparent uselessness of the NDE to an individual at the point of death does not preclude its evolution as a psychological device of utility to others.

\section{Temporal Occurrence of the NDE}

In discussing and dismissing reductionistic explanations of NDEs, Grosso differentiated NDEs from hallucinations induced by sensory deprivation and stress in a hospital setting by a variety of factors, one of which was the alleged time of occurrence of the experience: "hospital-induced" hallucinations are said to occur after the close brush with death, while NDEs are said to occur during the near-death event. But do we know in fact when the NDE occurs? In most cases, all we know is that upon recovery from a close brush with death, a person reports having had an experience. We have no way of determining the temporal location of that experience, except that it must have occurred before, or simultaneously with, the retelling of it.

The observation that many NDEs are recounted following close brushes with death tempts us to assume that the NDE occurred during the near-death event. However, while we may regard neardeath events as common correlates of NDEs, we are not justified in using the close brush with death as a criterion for the temporal occurrence of the NDE.

NDEs are often reported following near-death events that cannot be verified, or that were aborted before the experiencer came physiologically close to death. Among suicide attempters, in fact, NDE reports are more frequent among those who did not come close to death than among those who nearly died (Greyson, 1981b). If we allow near-death events to define the temporal occurrence of NDEs, then what do we make of these prototypical NDE reports that do not follow close brushes with death? If we choose to disregard the NDE report that does not follow a near-death event, then we also discard the argument for using near-death events to locate NDEs in time. That is, if the experiencer's testimony is not a valid criterion for having had an NDE, even in the absence of a close brush with death, then the correlation between near-death events and NDE reports is meaningless.

Sabom (1981) has argued that near-death events should be incorporated into the definition of an NDE to reduce the ambiguity of the concept of the phenomenon. It is certainly true that relying on verbal testimony as the sole criterion for an NDE, and disregarding the evidence for a close brush with death, may lead to ambiguity or contradiction. Individuals may report, after a close brush with death, 
that they did not have an NDE, and then later claim that they did have one after all; or they may report that they are not sure whether or not they had an NDE; or they may report that they think they had an NDE, but can't remember it. Did any of these individuals have NDEs. or did they just think that they did; and if the latter, how do we distinguish thinking that one had an NDE from actually having had one? These are difficult problems for near-death research, and the only reply at this point in our knowledge of NDEs may be that ambiguous criteria are all that can be demanded for a concept that is still as ambiguous as the NDE. As an analogy, one cannot multiply two numbers rounded off to the nearest tenth and demand a product accurate to the nearest hundredth. Any refinement of the definition of the NDE, such as inclusion of a documented near-death event as a necessary component, must be justified by empirical evidence of its validity. At this point we do not have such evidence.

But if a near-death event cannot be used to define logically the temporal location of the NDE, can it be used as a pragmatic guide to the time of occurrence of the experience? One might assert, for example, that close brushes with death are temporal correlates of most NDEs, or that they are temporal correlates of psychological states in which NDEs are most likely to occur. Either assertion connects NDEs with a high probability of occurring at a specific time, without allowing the close brush with death to define the temporal location of the NDE. These assertions, however, while possibly correct, are not yet substantiated by empirical data. It is equally consistent with the evidence to assert that a close brush with death merely inclines the individual to have the impression, upon recovery from the near-death event, that he or she had an NDE. That is, the NDE, while made more likely by the occurrence of a close brush with death, may still be elaborated only upon recovery from the near-death event. Such an explanation would account for the association between close brushes with death and subsequent NDE reports without specifying anything about the temporal location or duration of the NDE itself.

Attempts to ascertain the time of occurrence of an NDE by reference to external events fail for similar reasons. Some individuals reporting NDEs describe objective events, localizable in time and space, which they state they witnessed in their out-of-body state. Sabom (1981) considered such cases to be strong evidence for the objective reality of the NDE. However, such cases do not necessarily establish the time of occurrence of the NDE. Waking from a close brush with death with accurate knowledge of certain objective 
events, and then learning that those events actually occurred while one was ostensibly unconscious, may incline the individual, retroactively, to attribute the NDE to that period of unconsciousness. The causal relation, and hence the temporal sequence, may indeed progress from autoscopic NDE to paranormal acquisition of knowledge; but it can progress just as logically from paranormally acquired knowledge to impression that the knowledge was acquired during an NDE.

The question of when the NDE actually occurred is further complicated by the assertion of many individuals that their NDEs cannot be described in any temporal sequence. The component parts of the NDE are often recounted as having occurred all at once, or in no particular sequence, or in a changing or fluid order. NDE reports frequently include the statement that during the experience time stopped, or lost all meaning, or ceased to exist, or no longer constrained the experiencer. Noyes and Kletti (1976) described the temporal disintegration in NDEs by comparing normal consciousness to a movie filmstrip: in NDEs the frames appear isolated and disconnected from those preceding and following, and as a result lose their location in time.

The significance of our inability to localize the NDE in time is not only that it muddies Grosso's distinction between NDEs and "hospital-induced" hallucinations, but that it also invalidates Grosso's paradox of the biologically superfluous experience occurring when hope of revival is lost. If we cannot establish the temporal location of the NDE, then it may well occur during a period of normal vital functioning, either to prepare the threatened individual psychologically for an impending near-death event, or to help the survivor adapt psychologically to the consequences of the close brush with death.

\section{Psychological Function of an NDE Before the Near-Death Event}

Most psychological explanations of the NDE have assumed that the experience occurs prior to the near-death event, as a response to the threat of death. This interpretation was first elaborated by Pfister in a 1930 article recently translated into English by Kletti and Noyes (1981). Pfister proposed that persons faced with potentially inescapable danger attempt to exclude this unpleasant reality from their perceptions and replace it with pleasurable fantasies, which protect the individual from being paralyzed by emotional shock. Ehrenwald (1978) also viewed the NDE as a defense against the threat of death, the out-of-body experience being a denial of dependence on the endangered body, and the visions of departed acquain- 
tances being hallucinatory wish fulfillment and, again, a denial of the finality of death. Grosso rejected the wish-fulfillment hypothesis on the basis of NDE reports that contradict the experiencer's reported beliefs or desires regarding post-mortem survival. However, this cavalier dismissal of the role of expectation neglects the substantial ambivalence many people harbor towards death and an afterlife.

Hunter (1967) independently attributed the pleasant and transcendental NDE to denial of death, but also speculated that the passive acceptance of imminent death may be an intrinsically pleasurable state. He explained the life review as a regression to childhood memories in an attempt to escape from frightening present realities. Fisher (1970) echoed this interpretation of the life review as a retreat to a bygone world of pleasant childhood memories and fantasies, and saw the illusory restitution of lost body parts in amputees as a similar defensive mechanism.

Noyes and Kletti (1977) also explained the life review as an escape from threatening reality. In addition, however, they compared the absorption with images of one's past to the bereaved person's absorption with mementos of departed loved ones: they saw in the life review a process of anticipatory grieving over the impending loss of one's own life. The timeless quality of the life review was also interpreted as an escape from the tyranny of the imminence of death. In contrast to pathological conceptions of the life review, Butler (1963) wrote of it as a naturally occurring stage with constructive purposes. Though he too viewed the life review as precipitated by the realization of approaching death, he described the process not only as an escape, but as a device to resolve old conflicts, to reflect upon and reconsider the meaning of one's life, to revise one's perspective on past experience, and to separate real from neurotic guilt.

Grosso attacked the theory that NDEs represent a form of depersonalization in response to life-threatening danger on the grounds that NDEs differ from other types of depersonalization. Noyes, the primary proponent of the depersonalization hypothesis of NDEs, conceded that the NDE seems to be a unique form of depersonalization, particularly in its intense affect and positive effects on the personality (1981). While he acknowledged that depersonalization cannot explain all aspects of the NDE, he viewed the split of the threatened individual's personality into a calm, detached observer and a frantic, imperiled victim as a prototypical description of depersonalization, designed to protect the individual from the painful and disorganizing experience of physical death. Dlin (1980) saw such depersonalization also as the creation of a psycho- 
logical state that mimicked death, an attempt to avoid actual death by sacrificing a part of the self: the individual, having "died" psychologically, might be spared actual death.

Other authors have cited specific biological changes in the body near death and have concluded that the NDE may be a psychological mechanism having survival value. Krishnan (1981) noted that the brain may die if sensory input to it is stopped completely, and that as one approaches death, environmental isolation and progressive deterioration of the body's sense organs and nervous system threaten to isolate the brain completely. He speculated that the out-of-body experience might be a biological device to keep sensory input coming to the brain during a close brush with death. Watson (1974) cited evidence that one's ability to survive a close brush with death may depend on one's mental state: a calm state of mind may conserve one's energy resources and prolong life, whereas agitation might deplete these energy reserves. He speculated that the transcendental and peaceful NDE may be a psychological mechanism to assure conservation of energy in the face of death.

Thus the NDE, if it in fact occurs in the early stages of a close brush with death, when one's vital functioning is still intact, might serve a number of critical purposes, including a defensive exclusion of reality from perception, when that terrifying reality might otherwise paralyze the will; denial of the threat of death, in an effort to keep hope and rescue efforts alive; pleasurable wish fulfillment; grieving over the imminent loss of one's life; reassessment of one's life; submission to a psychological death in an attempt to preclude actual bodily death; stimulation to keep alive an otherwise deteriorating brain; and conservation of dwindling energy reserves.

\section{Psychological Function of an NDE After the Near-Death Event}

Most psychodynamic speculation on the function of the NDE, as noted above, has focused on the individual's response to the threat of imminent death. Some investigators, however, have assumed that the NDE is created upon recovery from the near-death event and have speculated on the role of the experience in adapting psychologically to having been close to death.

Pandey (1971) hypothesized that the idea of being in a near-death state, without one's usual control over consciousness and behavior, may be so repellent to some people that they develop an alternative fantasy to explain their experience while unconscious. She speculated that rather than accept that they had lost control over their 
bodies, or had become, even briefly, like a biological machine functioning without awareness, some individuals prefer to believe that their bodies had in fact ceased to function, but that they had continued to function independently of their lifeless bodies. In addition to providing a more palatable account of one's behavior while unconscious, Pandey also suggested that believing one had died may relieve some people's strong guilt feelings.

Soliman (1979) focused on the guilt one may have about surviving while others in similar situations died. He speculated that the survivors may delude themselves that they also died in order to rid themselves of this survivor guilt. Ehrenwald (1978) hypothesized that the serenity, peace of mind, and euphoria of the NDE may be due in part not to the experience of nearly dying, but rather to the experience of recovery. He suggested that only when the pain and suffering have ceased and the danger is past can the individual pass in to a state of tranquility, as a direct response to his or her survival.

Thus the NDE, if it in fact occurs only upon recovering from a close brush with death, may provide a more acceptable version of one's behavior during the near-death event; may relieve the individual's guilt over having survived the close brush with death; and may be an expression of the individual's relief at having survived the neardeath event.

\section{CONCLUSION}

Grosso asserted that an adequate explanation of the NDE must address all three puzzling components of the phenomenon: its consistency, its paranormal dimension, and its positive transformative effects. As noted above, psychological interpretations could address all three aspects of the NDE. That is not to say that a psychological explanation is correct; only that Grosso has dismissed the possibility of one being correct prematurely.

But the requirement that one theory explain all aspects of an NDE may be an impediment to our understanding if those phenomena we now call NDEs actually comprise several different experiences. Noyes (1981) has identified by factor analysis three distinct components of the NDE, which he has labeled hyperalertness, depersonalization, and mysticism. It is conceivable that the component parts of the NDE may have different causes and functions. Some features we now consider part of the prototypical NDE, such as visual hallucinations and panoramic memories, may be attributable eventually to organic brain dysfunction; other elements, such as feelings of painlessness 
and depersonalization symptoms, may be attributable to psychological defenses; and some aspects, such as veridical out-of-body perceptions and so-called flash-forwards, may not be comprehensible by any current physiological or psychological explanation. Grosso's insistence that one explanation encompass all aspects of the NDE is valid only if NDEs are indeed unitary phenomena. I suggest that we need not restrict our consideration of explanatory hypotheses until we have the data to support a unitary conception of the NDE.

Finally, Grosso asserted that an adequate scientific theory of NDEs, in addition to being consistent with all aspects of the NDE, must be consistent with the total system of knowledge, and must enable us to predict new features and ramifications of the explicanda. Given these requirements, we do not know enough about NDEs to provide a decisive theory, psychological or otherwise. But psychological explanations can satisfy the requirement of consistency with the reported phenomenon, and should not prematurely be pronounced near death.

\section{REFERENCES}

Arieti, S. Interpretation of Schizophrenia (Second Edition). New York: Basic Books, 1974.

Bowers, M. B., \& Freedman, D. X. "Psychedelic" experiences in acute psychoses. Archives of General Psychiatry, 1966, 15, 240-248.

Butler, R. N. The life review: an interpretation of reminiscence in the aged. Psychiatry, 1963, 26(1), 65-76.

Caplan, G. Principles of Preventive Psychiatry. New York: Basic Books, 1964.

Clark, W. H. Discussion of "Mystical states and the concept of regression." Psychedelic Review, 1966, 8, 76-81.

Dlin, B. M. The experience of surviving almost certain death. Advances in Psychosomatic Medicine, 1981, 19, 111-118.

Drab, K. The tunnel experience: reality or hallucination? Anabiosis, in press.

Ehrenwald, J. The ESP Experience: A Psychiatric Validation. New York: Basic Books, 1978.

Fenichel, O. The Psychoanalytic Theory of Neurosis. New York: Norton, 1945.

Fisher, S. Body Experience in Fantasy and Behavior. New York: Appleton-Century-Crofts, 1970.

Greyson, B. Near-death experiences and attempted suicide. Suicide and Life-Threatening Behavior, 1981, 11(1), 10-16. (a) 
Greyson, B. Empirical evidence bearing on the interpretation of neardeath experiences among suicide attempters. Paper presented at the American Psychological Association Annual Convention, Los Angeles, 1981. (b)

Grof, S., \& Halifax, J. The Human Encounter With Death. New York: Dutton, 1977.

Grosso, M. Toward an explanation of near-death phenomena. Anabiosis, 1981, 1(1), 3-26.

Hunter, R. C. A. On the experience of nearly dying. American Joumal of Psychiatry, 1967, 124(1), 84-88.

Kletti, R., \& Noyes, R., Jr. Mental states in mortal danger. Essence, $1981,5(1), 5-20$.

Krishnan, V. Near-death experiences: reassessment urged. Parapsychology Review, 1981, 12(4), 10-11.

Laing, R. D. The Politics of Experience. New York: Pantheon Books, 1967.

Lindemann, E. Symptomatology and management of acute grief. American Journal of Psychiatry, 1944, 101(2), 141-148.

Noyes, R., Jr. The encounter with life-threatening danger: its nature and impact. Essence, 1981, 5(1), 21-32.

Noyes, R., Jr., \& Kletti, R. Depersonalization in the face of lifethreatening danger: an interpretation. Omega, 1976, 7(2), 103-114.

Noyes, R., Jr., \& Kletti, R. Panoramic memory: a response to the threat of death. Omega, 1977, 8, 181-184.

Pandey, C. The need for the psychological study of clinical death. Omega, 1971, 2, 1-8.

Prince, R., \& Savage, C. Mystical states and the concept of regression. Psychedelic Review, 1966, 8, 59-75.

Sabom, M. B. The near-death experience: myth or reality? A methodological approach. Anabiosis, 1981, 1(1), 44-56.

Siegler, M., Osmond, H., \& Mann, H. Laing's models of madness. British Journal of Psychiatry, 1969, 115, 947-958.

Siirala, M. Schizophrenia: a human situation. American Journal of Psychoanalysis, 1963, 23, 39-58.

Soliman, P. Confrontation with death. Israel Annals of Psychiatry and Related Disciplines, 1979, 17(2), 149-164.

Stanford, R. G. An experimentally testable model for spontaneous psi events: I. Extrasensory events. Journal of the American Society for Psychical Research, 1974, 68(1), 34-57.

Stanford, R. G., \& Associates. A study of motivational arousal and self-concept in psi-mediated instrumental response. Journal of the American Society for Psychical Research, 1976, 70(2), 167-178. 
Watson, L. The Romeo Error: A Matter of Life and Death. Garden City, N.Y.: Anchor Press/Doubleday, 1974.

Yalom, I. D. The Theory and Practice of Group Psychotherapy (Second Edition). New York: Basic Books, 1975.

Requests for reprints to:

Dr. Bruce Greyson

Box 54

University of Michigan Hospital

1405 East Ann Street

Ann Arbor, Michigan 48109 